\title{
Radiographic lung volumes predict progression to COPD in smokers with preserved spirometry in SPIROMICS
}

\author{
Mehrdad Arjomandi ${ }^{1,2}$, Siyang Zeng ${ }^{1,2}$, Igor Barjaktarevic ${ }^{3}$, R. Graham Barr ${ }^{4}$, \\ Eugene R. Bleecker ${ }^{5}$, Russell P. Bowler ${ }^{6}$, Russell G. Buhr ${ }^{3,7}$, Gerard J. Criner $^{8}$, \\ Alejandro P. Comellas ${ }^{9}$, Christopher B. Cooper ${ }^{3,10}$, David J. Couper ${ }^{11}$, \\ Jeffrey L. Curtis ${ }^{12,13}$, Mark T. Dransfield ${ }^{14}$, MeiLan K. Han ${ }^{13}$, Nadia N. Hansel ${ }^{15}$, \\ Eric A. Hoffman ${ }^{10}$, Robert J. Kaner ${ }^{16}$, Richard E. Kanner ${ }^{17}$, Jerry A. Krishnan ${ }^{18}$, \\ Robert Paine $\mathrm{III}^{17}$, Stephen P. Peters ${ }^{19}$, Stephen I. Rennard ${ }^{20}$ and \\ Prescott G. Woodruff ${ }^{2}$, for the SPIROMICS Investigators
}

@ERSpublications

Radiographic lung volumes and related computed tomography measures that represent air trapping are associated with an accelerated decline in lung function and can identify susceptible smokers at increased risk of progressing to overt COPD http://bit.ly/32QqiKQ

Cite this article as: Arjomandi M, Zeng S, Barjaktarevic I, et al. Radiographic lung volumes predict progression to COPD in smokers with preserved spirometry in SPIROMICS. Eur Respir J 2019; 54: 1802214 [https://doi.org/10.1183/13993003.02214-2018].

ABSTRACT The characteristics that predict progression to overt chronic obstructive pulmonary disease (COPD) in smokers without spirometric airflow obstruction are not clearly defined.

We conducted a post hoc analysis of 849 current and former smokers ( $\geqslant 20$ pack-years) with preserved spirometry from the Subpopulations and Intermediate Outcome Measures in COPD Study (SPIROMICS) cohort who had baseline computed tomography (CT) scans of lungs and serial spirometry. We examined whether CT-derived lung volumes representing air trapping could predict adverse respiratory outcomes and more rapid decline in spirometry to overt COPD using mixed-effect linear modelling.

Among these subjects with normal forced expiratory volume in $1 \mathrm{~s}\left(\mathrm{FEV}_{1}\right)$ to forced vital capacity (FVC) ratio, CT-measured residual volume $\left(\mathrm{RV}_{\mathrm{CT}}\right)$ to total lung capacity $\left(\mathrm{TLC}_{\mathrm{CT}}\right)$ ratio varied widely, from $21 \%$ to $59 \%$. Over $2.5 \pm 0.7$ years of follow-up, subjects with higher $\mathrm{RV}_{\mathrm{CT}} / \mathrm{TLC}_{\mathrm{CT}}$ had a greater differential rate of decline in $\mathrm{FEV}_{1} / \mathrm{FVC}$; those in the upper $\mathrm{RV}_{\mathrm{CT}} / \mathrm{TLC}_{\mathrm{CT}}$ tertile had a $0.66 \%$ (95\% CI $0.06 \%-1.27 \%)$ faster rate of decline per year compared with those in the lower tertile $(\mathrm{p}=0.015)$ regardless of demographics, baseline spirometry, respiratory symptoms score, smoking status (former versus current) or smoking burden (pack-years). Accordingly, subjects with higher $\mathrm{RV}_{\mathrm{CT}} / \mathrm{TLC}_{\mathrm{CT}}$ were more likely to develop spirometric COPD (OR 5.7 (95\% CI 2.4-13.2) in upper versus lower $\mathrm{RV}_{\mathrm{CT}} / \mathrm{TLC}_{\mathrm{CT}}$ tertile; $\mathrm{p}<0.001)$. Other CT indices of air trapping showed similar patterns of association with lung function decline; however, when all CT indices of air trapping, emphysema, and airway disease were included in the same model, only $\mathrm{RV}_{\mathrm{CT}} / \mathrm{TLC}_{\mathrm{CT}}$ retained its significance.

Increased air trapping based on radiographic lung volumes predicts accelerated spirometry decline and progression to COPD in smokers without obstruction. 


\section{Introduction}

Chronic obstructive pulmonary disease (COPD) is a heterogeneous disease that affects only a fraction of those who smoke tobacco [1-4]. Although nearly all smokers have evidence of chronic airway inflammation $[5,6]$, only about $20 \%$ of them develop chronic airflow obstruction that meets the definition of COPD [1]. The origin of this widely variable susceptibility to develop COPD has not been well elucidated, and the ability to identify which smokers without airflow obstruction are at the highest risk for development of respiratory problems and lung function decline is of great interest for prognostication and intervention purposes.

Air trapping, defined as abnormally increased volume of air remaining in the lungs at the end of exhalation, is a manifestation of obstructive lung disease and is associated with increased dyspnoea, reduced functional capacity and higher mortality [7, 8]. However, its consequence in those at risk for COPD but with preserved spirometry (normal forced expiratory volume in $1 \mathrm{~s}\left(\mathrm{FEV}_{1}\right)$ to forced vital capacity (FVC) ratio) demands further examination. A recent retrospective study of the United States Veterans Administration electronic health records showed abnormal lung volumes and air trapping, as measured by plethysmography, to be present in $>30 \%$ of smokers with preserved spirometry and to be associated with adverse respiratory outcomes and progression to spirometric COPD [9]. However, there has been no prospective validation of the utility of lung volumes as predictor of future lung function decline and progression to overt COPD.

In this study, we hypothesised that in individuals at risk for COPD due to smoking but with preserved spirometry, those with increased ratio of residual volume (RV) to total lung capacity (TLC), an index that represents air trapping, would have faster rates of lung function decline and progression to develop spirometric COPD. To examine this hypothesis, we used computed tomography (CT)-derived measures of lung volumes and clinical data prospectively collected on current and former smokers without COPD from the National Heart, Lung, and Blood Institute-funded Subpopulations and Intermediate Outcome Measures in COPD Study (SPIROMICS) [10], and investigated whether CT measures of lung volumes representing air trapping could predict subsequent development of spirometric COPD and increased morbidity. We also examined whether other CT indices of air trapping, emphysema and airway disease had additional contributions towards the above outcomes beyond that from lung volumes.

\section{Methods}

Study design

The SPIROMICS multicentre observational study enrolled 2981 participants from 2010 through 2015 [10]. The study included persons 40-80 years of age who were either never-smoking healthy persons or current and former smokers who had a smoking history $\geqslant 20$ pack-years, with or without a clinical diagnosis of obstructive lung disease. Participants were categorised using the Global Initiative on Obstructive Lung Disease (GOLD) staging system according to the results on spirometry performed before and after four inhalations each of albuterol at a dose of $90 \mu \mathrm{g}$ per inhalation and ipratropium at a dose of $18 \mu \mathrm{g}$ per inhalation [11]. Current and former smokers who had a concomitant diagnosis of asthma were not excluded. Respiratory symptoms, exacerbation history, exercise capacity by 6-minute walk distance (6-MWD) testing, and CT scans of the lung were obtained, and subjects were followed for a target follow-up time of 3 years with planned annual serial spirometry and symptoms questionnaires, as previously described $[10,12]$. Lung volumes representing air trapping were measured from full inspiratory

Affiliations: 'San Francisco Veterans Affairs Healthcare System, San Francisco, CA, USA. ${ }^{2}$ Dept of Medicine, University of California, San Francisco, CA, USA. ${ }^{3}$ Dept of Medicine, David Geffen School of Medicine, University of California, Los Angeles, CA, USA. ${ }^{4}$ Columbia-Presbyterian Medical Center, New York, NY, USA. ${ }^{5}$ University of Arizona, College of Medicine, Tucson, AZ, USA. ${ }^{6}$ National Jewish Health Systems, Denver, CO, USA. ${ }^{7}$ Greater Los Angeles Veterans Affairs Healthcare System, Los Angeles, CA, USA. ${ }^{8}$ Temple University, Philadelphia, PA, USA. ' University of lowa, lowa City, IA, USA. ${ }^{10}$ Dept of Physiology, David Geffen School of Medicine, University of California, Los Angeles, CA, USA. ${ }^{11}$ University of North Carolina, Chapel Hill, NC, USA.

${ }^{12}$ Medical Service, VA Ann Arbor Healthcare System, Ann Arbor, MI, USA. ${ }^{13}$ Department of Internal Medicine, University of Michigan, Ann Arbor, MI, USA. ${ }^{14}$ University of Alabama at Birmingham, Birmingham, AL, USA.

${ }^{15}$ Johns Hopkins Medical Institute, Baltimore, MD, USA. ${ }^{16}$ Weill Cornell Weill Cornell Medical Center, New York, NY, USA. ${ }^{17}$ University of Utah, Salt Lake City, UT, USA. ${ }^{18}$ University of Illinois at Chicago, Chicago, IL, USA. ${ }^{19}$ Wake Forest School of Medicine, Winston-Salem, NC, USA. ${ }^{20}$ BioPharmaceuticals R\&D, AstraZeneca, Cambridge, UK.

Correspondence: Mehrdad Arjomandi, Division of Pulmonary, Critical Care, Allergy and Immunology, and Sleep Medicine, University of California, San Francisco, San Francisco Veterans Affairs Medical Center. Building 203, Room 3A-128, Mailstop 111-D, 4150 Clement Street, San Francisco, CA 94121, USA. E-mail: mehrdad.arjomandiQucsf.edu 
(TLC) and full expiratory (RV) CT imaging of lungs. Other CT indices of air trapping, emphysema, and airway disease were also measured as described below.

From the 849 current and former smokers with preserved spirometry $\left(\mathrm{FEV}_{1} / \mathrm{FVC} \geqslant 0.70\right.$ after bronchodilator use and FVC equal to or above the predicted lower limit of normal [13], complete data for this analysis were available for 814 subjects (figure 1). CT-measured lung volumes with high confidence in their accuracy were available from 618 of the 814 subjects as described in the supplementary appendix and shown in supplementary figures S1 and S2. Using this cohort (described in supplementary table S1), we conducted a post hoc analysis to determine whether baseline radiographically measured lung volumes representing air trapping (ratio of CT-measured $\mathrm{RV}$ to $\mathrm{TLC}\left(\mathrm{RV}_{\mathrm{CT}} / \mathrm{TLC}_{\mathrm{CT}}\right)$ ) could predict more rapid decline in spirometry to overt COPD and worse respiratory symptoms.

\section{CT Indices of lung volumes, air trapping, emphysema and small airways}

The detailed protocol and quality assessment of SPIROMICS CT scans have been described previously [14]. Briefly, SPIROMICS has an established quantitative CT lung assessment system (QCT-LAS), which includes scanner-specific imaging protocols for lung assessment at TLC and RV. Written breath-holding instructions were supplied to the CT technologists, who were instructed to coach the subject, as in a pulmonary function laboratory, to achieve both TLC and RV with a series of preceding deep inspirations. To provide imaging speeds that allow proper breath-holds from subjects, only 64-detector rows or higher scanners were used.

In addition to $\mathrm{RV}_{\mathrm{CT}} / \mathrm{TLC}_{\mathrm{CT}}$, other $\mathrm{CT}$ indices of air trapping, including the percentage of the lung voxels with attenuation $<-856 \mathrm{HU}$ on the expiratory $\mathrm{CT}$ images $\left(\operatorname{Exp}_{-856}\right)[15,16]$ and parametric response mapping of functional small airway disease $\left(\mathrm{PRM}^{\mathrm{fSAD}}\right)[17,18]$, were also used in the analysis. Moreover, measures of emphysema including the percentage of the lung voxels on inspiratory CT images with attenuation <-950 HU (Insp-950) and parametric response mapping of emphysema $\left(\mathrm{PRM}^{\mathrm{EMPH}}\right)[17,18]$, and measures of airway disease including the average and thickest values for the square root of wall area of a hypothetical airway with $10 \mathrm{~mm}$ internal perimeter $\left(P_{\mathrm{i} 10}\right)$ [19] were also examined as additional predictors in the analysis.

\section{Statistical and data analysis}

The distribution of $\mathrm{RV}_{\mathrm{CT}} / \mathrm{TLC}_{\mathrm{CT}}$ was computed and its correlations with airflow obstruction indices $\left(\mathrm{FEV}_{1} / \mathrm{FVC}\right.$ and $\left.\mathrm{FEV}_{1}\right)$ were examined using the Pearson correlation test. To control for age, sex, height and weight covariates when examining the raw $\mathrm{RV}_{\mathrm{CT}} / \mathrm{TLC}_{\mathrm{CT}}$ values, partial correlations corrected for

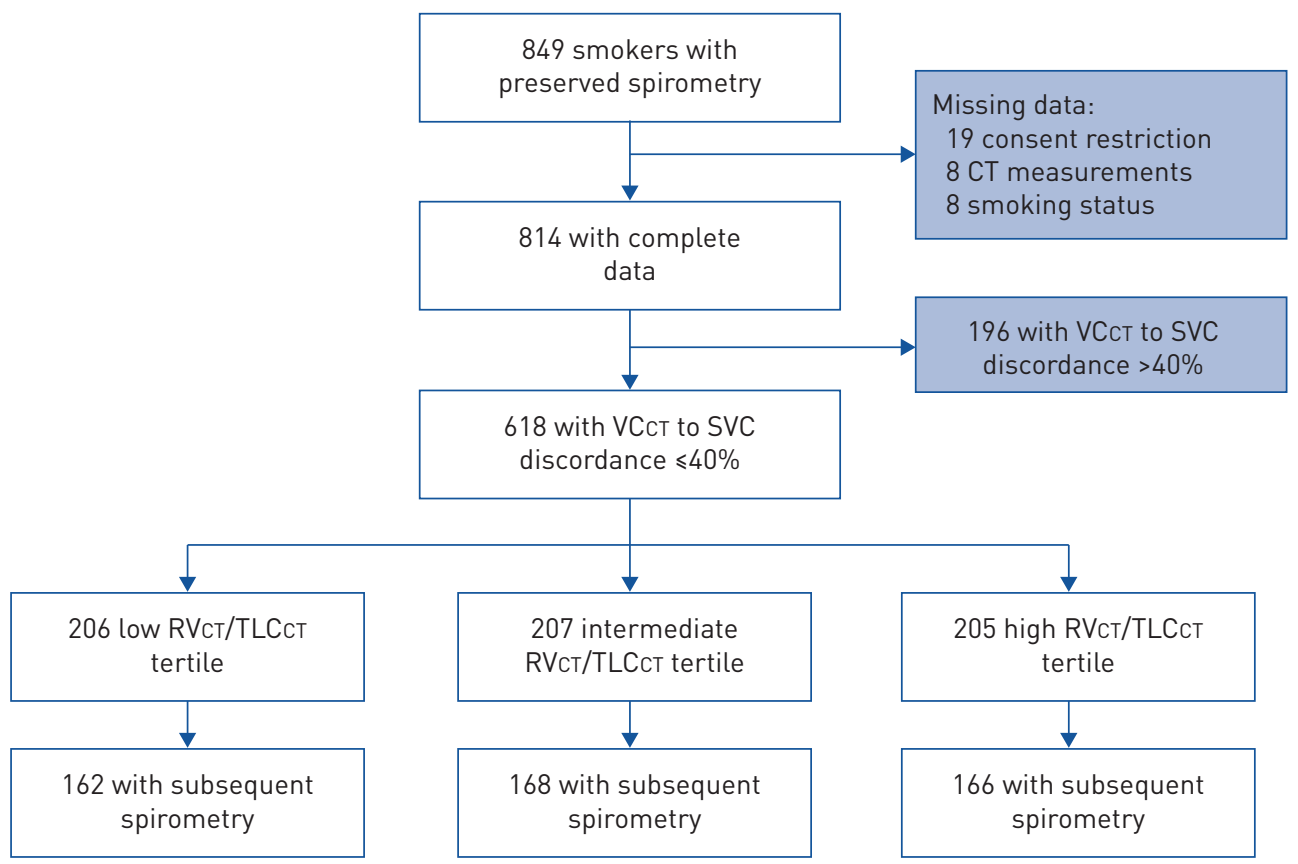

FIGURE 1 Subject flow. CT: computed tomography; SVC: slow vital capacity; $V_{C T}$ : CT-measured vital capacity; $\mathrm{RV}_{\mathrm{CT}} / \mathrm{TLC}_{\mathrm{CT}}$ : CT-measured residual volume to total lung capacity ratio. 
covariates were derived and examined [20]. To examine these distributions in more detail, airflow indices were partitioned in 5\% increments and summary statistics were calculated across each partition.

Outcome variables, including spirometric indices, symptoms (modified Medical Research Council dyspnoea scale (mMRC), COPD assessment test (CAT), Saint George's Respiratory Questionnaire (SGRQ) and Short Form 12-item Survey (SF12)), body-mass index, airflow obstruction, dyspnoea and exercise capacity (BODE) index, exercise capacity (6-MWD test) and respiratory exacerbations (frequency and time to event) were examined longitudinally. Changes in the outcomes were calculated by subtracting the subsequent visits (V2, V3 or V4) outcome values from those of baseline visit (V1), and then analysed using mixed effect modelling as described below.

Because there are no validated reference values for CT-measured lung volumes, we divided the subjects into three equal groups based on their $\mathrm{RV}_{\mathrm{CT}} / \mathrm{TLC}_{\mathrm{CT}}$ to form distinct categories of low, intermediate, and high $\mathrm{RV}_{\mathrm{CT}} / \mathrm{TLC}_{\mathrm{CT}}$, with the assumption that low and high $\mathrm{RV}_{\mathrm{CT}} / \mathrm{TLC}_{\mathrm{CT}}$ tertile groups would likely represent those subjects with normal and abnormal lung volumes, respectively. We used these tertile groups in the analysis as a categorical variable that would represent risk of progression to spirometric COPD.

The effects of $\mathrm{RV}_{\mathrm{CT}} / \mathrm{TLC}_{\mathrm{CT}}$ (both as a continuous and as a categorical variable) on changes in outcomes were examined using mixed-effect linear regression, with a nested random subject and study site effect, and fixed effect variables, including age, sex, height, weight, smoking status (current versus former), smoking burden (pack-years of smoking), corresponding baseline lung function or symptom or activity measurements (e.g. baseline $\mathrm{FEV}_{1} / \mathrm{FVC}$ when evaluating change in $\mathrm{FEV}_{1} / \mathrm{FVC}$ as an outcome or baseline mMRC when evaluating change in mMRC as an outcome), and follow-up time to repeat outcome measurement as described in the supplementary appendix. Interaction models were fit with the inclusion of the main effect for 1) follow-up time and 2) smoking status (current versus former smoker), and their interactions with $\mathrm{RV}_{\mathrm{CT}} / \mathrm{TLC}_{\mathrm{CT}}$ strata. To demonstrate statistical significance, p-values from mixed-effect linear regression modelling, as well as the $95 \%$ confidence intervals for comparisons of each $\mathrm{RV}_{\mathrm{CT}} / \mathrm{TLC}_{\mathrm{CT}}$ category effect estimate to that of the reference value, were calculated.

The analysis of association between progression to spirometric COPD and $\mathrm{RV}_{\mathrm{CT}} / \mathrm{TLC}_{\mathrm{CT}}$ was performed using mixed-effect logistic regression modelling with a nested random time and site effect, and fixed effect variables including age, sex, height, weight, smoking status (former versus current smoking), and smoking burden (pack-years of smoking).

To examine the relevance of $\mathrm{RV}_{\mathrm{CT}} / \mathrm{TLC}_{\mathrm{CT}}$ in the risk-prediction model for COPD development, we performed receiver operating characteristic (ROC) analysis and calculated its incremental contribution to the model beyond that of other covariates.

Cox proportional hazards regression modelling was used to analyse the association of $\mathrm{RV}_{\mathrm{CT}} / \mathrm{TLC}_{\mathrm{CT}}$ and CT indices of air trapping with time to the first hospitalisation. In addition, the association of those indices with number of severe respiratory exacerbations, as defined by number of emergency room and hospital admissions, were analysed using mixed-effect Poisson regression modelling to determine the incident rate ratios (IRR) of such events with consideration of follow-up time and study site.

We performed sensitivity analyses by simultaneous inclusion of variables that could act as confounders as additional terms in the regression models including hip-to-waist ratio and bronchodilator responsiveness $\left(\geqslant 12 \%\right.$ and $\geqslant 200 \mathrm{~mL}$ increase in $\mathrm{FEV}_{1}$ after bronchodilator administration). Separate sensitivity analyses were performed to evaluate the effect of presence or absence of respiratory symptoms (as measured by CAT questionnaire score of $<$ versus $\geqslant 10$ ) on associations of $\mathrm{RV}_{\mathrm{CT}} / \mathrm{TLC}_{\mathrm{CT}}$ and other $\mathrm{CT}$ air trapping indices with lung function outcomes. Additional sensitivity analyses were also performed by excluding patients with specific characteristics that could act as confounders, including smoking status (current versus former smoker), obesity or asthma separately.

\section{Results}

Correlation between baseline lung volumes and airflow indices

Among the 618 subjects with high concordance between CT-measured vital capacity $\left(\mathrm{VC}_{\mathrm{CT}}\right)$ and slow vital capacity (SVC), baseline $\mathrm{RV}_{\mathrm{CT}} / \mathrm{TLC}_{\mathrm{CT}}$ had weak-to-moderate inverse correlations with baseline $\mathrm{FEV}_{1}$ / FVC and $\mathrm{FEV}_{1}$ (covariate-corrected correlations of 0.21 and 0.28 , respectively; $\mathrm{p}<0.001$ ) (figure 2) (supplementary table S2). Nevertheless, $\mathrm{RV}_{\mathrm{CT}} / \mathrm{TLC}_{\mathrm{CT}}$ had a wide distribution across normal ranges of these airflow indices spanning from $21 \%$ to $59 \%$. This distribution corresponded to maximum coefficient of variations (standard deviation to mean ratio) of $19.3 \%$ and $20.5 \%$ across $5 \%$ (percent predicted) increments of $\mathrm{FEV}_{1} / \mathrm{FVC}$ and $\mathrm{FEV}_{1}$, respectively (figure 2). 

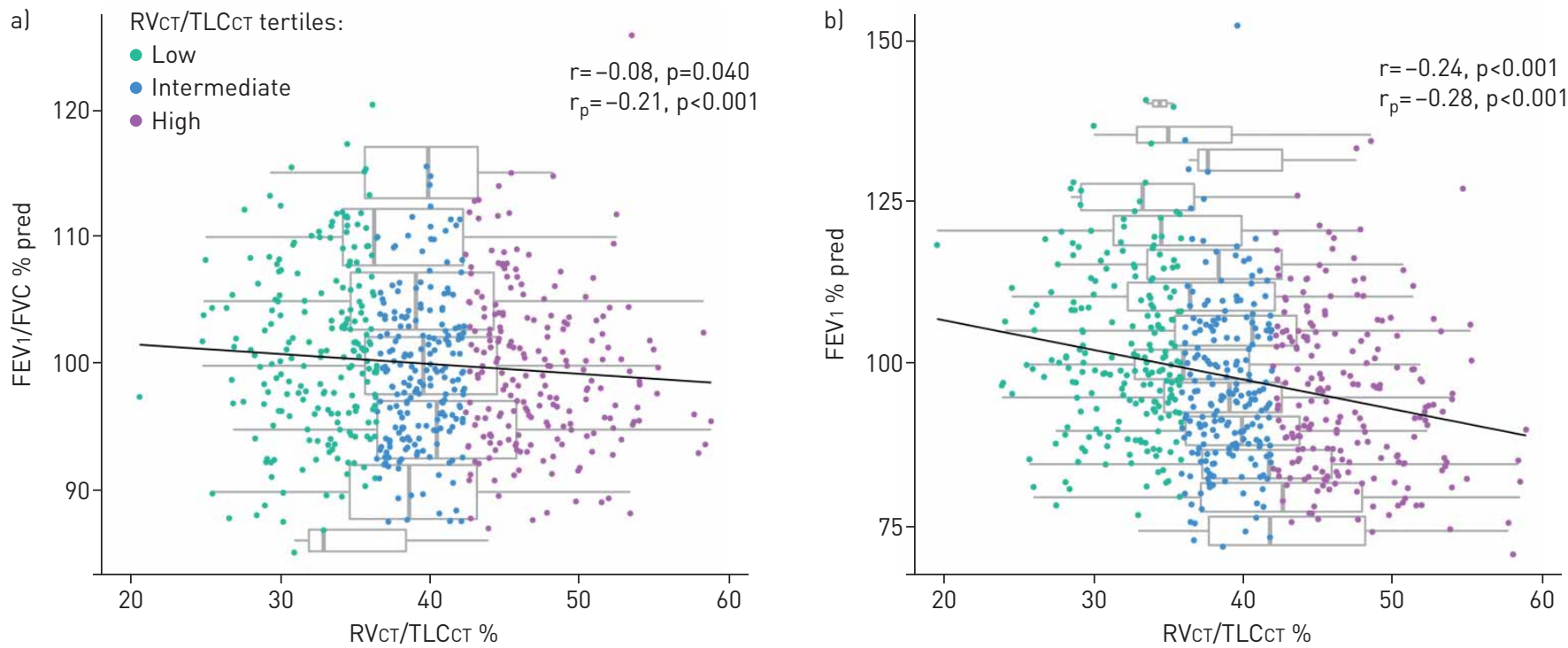

FIGURE 2 Correlation between computed tomography-measured residual volume to total lung capacity ratio (RV $\left.\mathrm{R}_{\mathrm{CT}} / \mathrm{TLC}_{\mathrm{CT}}\right)$ and forced expiratory volume in $1 \mathrm{~s}\left(\mathrm{FEV}_{1}\right) /$ forced vital capacity $(\mathrm{FVC})$ or $\mathrm{FEV}_{1}$ in smokers with preserved spirometry. Boxplots show the distribution of $\mathrm{RV}_{\mathrm{CT}} / \mathrm{TLC}_{\mathrm{CT}}$ (raw value) by $5 \%$ increments in $\mathrm{FEV}_{1} / \mathrm{FVC} \%$ predicted (Panel a), and $5 \%$ increments in $\mathrm{FEV} \%$ predicted (Panel b). Subjects were stratified into tertiles of $\mathrm{RV}_{\mathrm{CT}} / \mathrm{TLC}_{\mathrm{CT}}$ represented by green, blue and magenta for low, intermediate, and high $\mathrm{RV}_{\mathrm{CT}} / \mathrm{TLC}_{\mathrm{CT}}$ strata, respectively. The black line represents the regression line for all the points. $r$ : correlation coefficient; $r_{p}$ : partial correlation, which is the correlation coefficient between the dependent variable and the targeted independent variable with the effect of other controlling random variables removed.

\section{Association of lung volumes with progression to spirometric COPD}

Follow-up spirometry was available in 496 out of 618 subjects with high $\mathrm{VC}_{\mathrm{CT}}$ and SVC concordance. The median follow-up time from baseline spirometry (V1) to the last spirometry available was 2.7 years (interquartile range from 2.0 to 3.0 years and total range from 0.5 to 4.2 years; average follow-up time was $2.5 \pm 0.7$ years). Among the 496 subjects with at least one follow-up spirometry, 295 had two and 157 had three follow-up spirometries (table 1). The average raw value of $\mathrm{RV}_{\mathrm{CT}} / \mathrm{TLC}_{\mathrm{CT}}$ was $40 \pm 7 \%$ for the entire cohort, and $33 \pm 3 \%, 40 \pm 2 \%$ and $48 \pm 4 \%$ for the low, intermediate and high tertiles, respectively. Overall, $16.7 \%$ of the 496 subjects progressed to meet the spirometric definition of COPD during the median 2.7 years of follow up (unadjusted proportions of $6.2 \%, 16.1 \%$ and $27.7 \%$ for low, intermediate and high $\mathrm{RV}_{\mathrm{CT}} / \mathrm{TLC}_{\mathrm{CT}}$ groups, respectively; table 1).

During this follow-up period, and after adjustment for covariates (age, sex, height, weight, smoking status, smoking burden and baseline $\left.\mathrm{FEV}_{1} / \mathrm{FVC}\right), \mathrm{FEV}_{1} / \mathrm{FVC}$ ratio declined in an $\mathrm{RV}_{\mathrm{CT}} / \mathrm{TLC}_{\mathrm{CT}}$-dependent manner such that a $10 \%$ higher baseline $\mathrm{RV}_{\mathrm{CT}} / \mathrm{TLC}_{\mathrm{CT}}$ was associated with a $1.1 \%$ higher absolute decline in $\mathrm{FEV}_{1} / \mathrm{FVC}$ over the follow-up period $(\mathrm{p}<0.001)$ (tables 2 and 3 and figure $3 \mathrm{a}$ ). Accordingly, subjects with higher baseline $\mathrm{RV}_{\mathrm{CT}} / \mathrm{TLC}_{\mathrm{CT}}$ were more likely to develop spirometric COPD (table 4). For example, a $1 \%$ higher absolute $\mathrm{RV}_{\mathrm{CT}} / \mathrm{TLC}_{\mathrm{CT}}$ value on baseline CT resulted in $10.8 \%$ higher likelihood of developing spirometric COPD during the follow-up period (OR (95\%CI) 1.108 (1.056-1.162); p<0.001), which translates to nearly tripling the likelihood of developing COPD for every $10 \%$ higher $\mathrm{RV}_{\mathrm{CT}} / \mathrm{TLC}_{\mathrm{CT}}$ (OR (95\%CI) 2.779 (1.721-4.486); $\mathrm{p}<0.001)$.

To better understand the risk associated with developing COPD in smokers with preserved spirometry, we examined the likelihood of lung function decline to spirometric COPD for subjects in low, intermediate and high tertiles of $\mathrm{RV}_{\mathrm{CT}} / \mathrm{TLC}_{\mathrm{CT}}$. We found that subjects with high $\mathrm{RV}_{\mathrm{CT}} / \mathrm{TLC}_{\mathrm{CT}}$ had greater decline compared with those with intermediate $\mathrm{RV}_{\mathrm{CT}} / \mathrm{TLC}_{\mathrm{CT}}$, and those with intermediate $\mathrm{RV}_{\mathrm{CT}} / \mathrm{TLC}_{\mathrm{CT}}$ had greater decline compared with those with low $\mathrm{RV}_{\mathrm{CT}} / \mathrm{TLC}_{\mathrm{CT}}(\mathrm{p}=0.005)$ (table 3 and figure 4). Overall, subjects with high $\mathrm{RV}_{\mathrm{CT}} / \mathrm{TLC}_{\mathrm{CT}}(\geqslant 42.7 \%$ absolute value) were nearly 6-times more likely to develop COPD compared with those with low $\mathrm{RV}_{\mathrm{CT}} / \mathrm{TLC}_{\mathrm{CT}}(\leqslant 36.6 \%$ absolute value) over the follow-up period (OR (95\%CI) 5.689 (2.446-13.228); p<0.001) (table 4). Furthermore, ROC analyses showed that inclusion of $\mathrm{RV}_{\mathrm{CT}} / \mathrm{TLC}_{\mathrm{CT}}$ in the models improved the area under the curve (AUC) beyond the contribution of other covariates (including age and sex) (supplementary table S3).

The $\mathrm{RV}_{\mathrm{CT}} / \mathrm{TLC}_{\mathrm{CT}}$ and follow-up time interaction analysis showed the rate of decline in $\mathrm{FEV}_{1} / \mathrm{FVC}$ to be greater in those with high $\mathrm{RV}_{\mathrm{CT}} / \mathrm{TLC}_{\mathrm{CT}}$ compared with those with low (or intermediate) $\mathrm{RV}_{\mathrm{CT}} / \mathrm{TLC}_{\mathrm{CT}}$ (a differential $0.66 \%(95 \% \mathrm{CI} 0.06 \%-1.27 \%)$ increase in the rate of decline per year; $\mathrm{p}=0.015$ ) (figure $3 \mathrm{~b}$ and supplementary table S4). 
TABLE 1 Characteristics of smoker subjects with preserved spirometry who had follow-up spirometry

Demographics

Follow-up spirometry $n$

Age years

Female sex $n(\%)$

Height $\mathrm{cm}$

BMI kg/m²

Years of follow-up

Current smoker n (\%)

Smoking history pack-years

Baseline spirometric indices

FEV $_{1} \mathrm{~L}$

$\mathrm{FEV}_{1} \%$ pred

FVC L

FVC \% pred

$\mathrm{FEV}_{1} / \mathrm{FVC} \%$

$\mathrm{FEV}_{1} / \mathrm{FVC} \%$ pred

$\mathrm{FEF}_{25-75 \% \mathrm{~L}}$

$\mathrm{FEF}_{25-75 \%} \%$ pred

$\mathrm{FEF}_{75 \% \mathrm{~L}}$

Expiratory time on spirometry s

Reversibility in $\mathrm{FEV}_{1} \mathrm{~mL}$

Reversibility in $\mathrm{FEV}_{1} \%$

Bronchodilator responsiveness by $\mathrm{FEV}_{1} \mathrm{n}$

$\%$

SVC L

IC L

IRV L

Baseline CT indices

$\mathrm{TLC}_{\mathrm{CT}} \mathrm{L}$

$\mathrm{RV}_{\mathrm{CT}} \mathrm{L}$

$\mathrm{RV} / \mathrm{TLC}_{\mathrm{CT}} \%$

$\mathrm{VC}_{\mathrm{CT}} \mathrm{L}$

Average $P_{\mathrm{i} 10}$

Thickest $P_{\mathrm{i} 10}$

PRM $^{\text {EMPH }}$

PRM $^{\text {fSAD }}$

Exp-856

Insp_950

Activity levels and symptom scores

6-MWD m

BODE index

CAT score

mMRC

SGRQ total score

SGRQ symptom score

SGRQ activity score
496

$61.1 \pm 9.6$

162

$56.4 \pm 8.9$

73 (45.1)

$170.6 \pm 9.3$

$29.4 \pm 4.7$

$2.4 \pm 0.7$

$28.9 \pm 5.1$

$2.5 \pm 0.7$

232 (46.8)

$43.4 \pm 23.4$

$86(53.1)$

$40.5 \pm 26.1$

$2.81 \pm 0.69$

$98 \pm 12$

$3.63 \pm 0.89$

$97 \pm 12$

$77 \pm 5$

$100 \pm 6$
$2.68 \pm 0.98$

$107 \pm 34$

$0.97 \pm 0.47$

$9.66 \pm 3.43$

$160 \pm 143$

$6 \pm 6$

60 (12.1)

$3.69 \pm 0.94$

$2.80 \pm 0.72$

$1.91 \pm 0.67$

$4.73 \pm 1.08$

$1.88 \pm 0.50$

$40 \pm 7$

$2.84 \pm 0.76$

$3.701 \pm 0.082$

$3.815 \pm 0.114$

$0.35 \pm 1.07$

$6.93 \pm 6.22$

$6.46 \pm 6.03$

$1.82 \pm 2.04$

$442.1 \pm 90.6$

$0.40 \pm 0.76$

$10.9 \pm 8.2$

$0.71 \pm 0.81$

$23.5 \pm 18.8$

$35.5 \pm 25.7$

$32.9 \pm 23.3$
$3.13 \pm 0.69$

$102 \pm 12$

$3.97 \pm 0.91$

$100 \pm 12$

$79 \pm 5$

$101 \pm 7$
$3.22 \pm 1.05$

$117 \pm 38$

$1.21 \pm 0.53$

$9.62+3.38$

$154 \pm 142$

$5 \pm 5$

12 (7.4)

$4.04 \pm 0.96$

$3.02 \pm 0.72$

$2.08 \pm 0.70$

$4.86 \pm 1.09$

$1.59 \pm 0.39$

$33 \pm 3$

$3.27 \pm 0.75$

$3.692 \pm 0.083$

$3.809 \pm 0.112$

$0.22 \pm 0.80$

$3.33 \pm 3.10$

$3.11 \pm 2.92$

$1.91 \pm 2.36$

$453.2 \pm 89.2$

$0.36 \pm 0.69$

$9.7 \pm 7.0$

$0.71 \pm 0.84$

$21.5 \pm 16.0$

$33.2 \pm 23.5$

$30.9 \pm 21.1$
168

$60.7 \pm 9.5$

90 (53.6)

$169.7 \pm 9.1$

$28.7 \pm 5.2$

$2.5 \pm 0.6$

75 (44.6)

$43.1 \pm 21.1$

$2.80 \pm 0.60$

$97+12$

$3.64 \pm 0.80$

$97 \pm 12$

$77 \pm 4$

$100 \pm 6$

$2.59 \pm 0.84$

$103 \pm 29$

$0.92 \pm 0.38$

$10.10 \pm 3.69$

$158 \pm 132$

$6 \pm 5$

20 (11.9)

$3.70 \pm 0.83$

$2.82 \pm 0.67$

$1.92 \pm 0.64$

$4.74 \pm 1.06$

$1.87 \pm 0.43$

$40 \pm 2$

$2.86 \pm 0.65$

$3.697 \pm 0.080$

$3.806 \pm 0.101$

$0.25 \pm 0.65$

$6.02 \pm 4.79$

$5.67 \pm 4.52$

$1.69 \pm 1.51$

$442.5 \pm 92.3$

$0.44 \pm 0.84$

$12.0 \pm 8.6$

$0.74 \pm 0.86$

$25.9 \pm 20.6$

$38.1 \pm 27.8$

$35.8 \pm 25.4$

$\begin{array}{cc}166 & \\ 66.0 \pm 7.9 & <0.001 \\ 98(59.0) & 0.038 \\ 167.9 \pm 9.1 & 0.021 \\ 28.6 \pm 5.3 & 0.329 \\ 2.6 \pm 0.6 & 0.079 \\ 71(42.8) & 0.138 \\ 46.5 \pm 22.6 & 0.065 \\ & \\ 2.50 \pm 0.63 & <0.001 \\ 95 \pm 12 & <0.001 \\ 3.29 \pm 0.84 & <0.001 \\ 94 \pm 12 & <0.001 \\ 76 \pm 5 & <0.001 \\ 100 \pm 6 & 0.089 \\ 2.25 \pm 0.77 & <0.001 \\ 101 \pm 33 & <0.001 \\ 0.78 \pm 0.36 & <0.001 \\ 9.25 \pm 3.16 & 0.077 \\ 166 \pm 154 & 0.769 \\ 7 \pm 7 & 0.007 \\ 28(16.9) & 0.031 \\ & \\ 3.32 \pm 0.89 & <0.001 \\ 2.56 \pm 0.70 & <0.001 \\ 1.72 \pm 0.61 & <0.001 \\ & \\ 4.58 \pm 1.08 & 0.062 \\ 2.17 \pm 0.51 & <0.001 \\ 48 \pm 4 & <0.001 \\ 2.41 \pm 0.62 & <0.001 \\ 3.715 \pm 0.083 & 0.030 \\ 3.829 \pm 0.126 & 0.142 \\ 0.59 \pm 1.51 & 0.002 \\ 11.25 \pm 7.14 & <0.001 \\ 10.54 \pm 7.19 & <0.001 \\ 1.88 \pm 2.16 & 0.580 \\ & \\ 430.7 \pm 89.5 & 0.080 \\ 0.39 \pm 0.74 & 0.609 \\ 10.79 \pm 8.79 & 0.032 \\ 0.68 \pm 0.75 & 0.812 \\ 23.1 \pm 19.4 & 0.116 \\ 35.3 \pm 25.6 & 0.235 \\ 31.9 \pm 23.1 & 0.147\end{array}$




\begin{tabular}{|c|c|c|c|c|c|}
\hline Characteristics & All subjects & Subjects with low $\mathrm{RV}_{\mathrm{CT}} / \mathrm{TLC}_{\mathrm{CT}}$ & Subjects with intermediate $\mathrm{RV}_{\mathrm{CT}} / T \mathrm{TC}_{\mathrm{CT}}$ & Subjects with high $\mathbf{R V}_{\mathrm{CT}} / \mathrm{TLC}_{\mathrm{CT}}$ & $\mathrm{p}$-value (ANOVA) \\
\hline SGRQ impact score & $14.9 \pm 16.7$ & $12.6 \pm 13.2$ & $17.0 \pm 18.2$ & $15.2 \pm 18.0$ & 0.068 \\
\hline SF12 physical component & $51.1 \pm 6.3$ & $51.7 \pm 5.8$ & $50.5 \pm 7.1$ & $51.0 \pm 6.0$ & 0.221 \\
\hline SF12 physical functioning & $50.8 \pm 7.0$ & $51.4 \pm 6.3$ & $50.0 \pm 7.5$ & $50.9 \pm 7.0$ & 0.181 \\
\hline \multicolumn{6}{|l|}{ Follow-up spirometry $\#$} \\
\hline Age years & $63.2 \pm 9.8$ & $58.3 \pm 9.0$ & $62.8 \pm 9.7$ & $68.3 \pm 7.8$ & $<0.001$ \\
\hline Height $\mathrm{cm}$ & $169.0 \pm 9.9$ & $169.8 \pm 11.3$ & $169.5 \pm 8.9$ & $167.6 \pm 9.3$ & 0.098 \\
\hline $\mathrm{FEV}_{1} \mathrm{~L}$ & $2.69 \pm 0.69$ & $3.00 \pm 0.68$ & $2.67 \pm 0.61$ & $2.40 \pm 0.64$ & $<0.001$ \\
\hline $\mathrm{FEV}_{1} \%$ pred & $96 \pm 14$ & $100 \pm 12$ & $95 \pm 14$ & $94 \pm 14$ & $<0.001$ \\
\hline FVC L & $3.57 \pm 0.90$ & $3.87 \pm 0.90$ & $3.57 \pm 0.84$ & $3.28 \pm 0.87$ & $<0.001$ \\
\hline FVC \% pred & $98 \pm 14$ & $100 \pm 13$ & $97 \pm 14$ & $97 \pm 16$ & 0.133 \\
\hline $\mathrm{FEV}_{1} / \mathrm{FVC} \%$ & $75 \pm 6$ & $78 \pm 5$ & $75 \pm 6$ & $73 \pm 6$ & $<0.001$ \\
\hline $\mathrm{FEV}_{1} / \mathrm{FVC} \%$ pred & $98 \pm 8$ & $100 \pm 7$ & $98 \pm 8$ & $97 \pm 8$ & $<0.001$ \\
\hline $\mathrm{FEF}_{25-75 \% \mathrm{~L}}$ & $2.41 \pm 1.02$ & $2.98 \pm 1.06$ & $2.31 \pm 0.89$ & $1.96 \pm 0.82$ & $<0.001$ \\
\hline $\mathrm{FEF}_{25-75 \%} \%$ pred & $98 \pm 34$ & $108 \pm 32$ & $94 \pm 31$ & $91 \pm 35$ & $<0.001$ \\
\hline $\mathrm{FEF}_{75 \%} \mathrm{~L}$ & $0.83 \pm 0.46$ & $1.07 \pm 0.50$ & $0.79 \pm 0.41$ & $0.65 \pm 0.34$ & $<0.001$ \\
\hline Expiratory time on spirometry s & $11.03 \pm 4.82$ & $10.59 \pm 4.51$ & $11.37 \pm 4.69$ & $11.11 \pm 5.20$ & 0.328 \\
\hline \multicolumn{6}{|c|}{ Subjects who progressed to spirometric COPD at follow-up visits } \\
\hline Visit 2 n (\%) & $58(11.7)$ & $9(5.6)$ & $23(13.7)$ & $26(15.7)$ & 0.010 \\
\hline Visit 3 n (\%) & $62(21.0)$ & $7(8.8)$ & 19 (18.5) & $36(32.1)$ & $<0.001$ \\
\hline Visit $4 \mathrm{n}(\%)$ & $34(21.4)$ & $6(13.6)$ & $14(25.5)$ & $14(23.3)$ & 0.329 \\
\hline Last Follow-up n (\%) & 83 (16.7) & $10(6.2)$ & $27(16.1)$ & $46(27.7)$ & $<0.001$ \\
\hline After 1 year $\mathrm{n}(\%)$ & 58 (11.7) & $9(5.6)$ & $23(13.7)$ & $26(15.7)$ & 0.010 \\
\hline After 2 years $\mathrm{n}(\%)$ & 59 (13.4) & $7(5.2)$ & $23(15.1)$ & $29(19.1)$ & 0.001 \\
\hline After 3 years $n(\%)$ & $53(19.6)$ & $6(8.6)$ & $19(19.0)$ & $28(28.0)$ & 0.006 \\
\hline
\end{tabular}

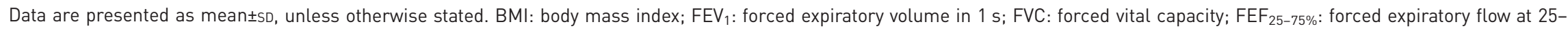
$75 \%$ of $\mathrm{FVC}_{\text {; }} \mathrm{FEF}_{75 \%}$ : forced expiratory flow at $75 \%$ of $\mathrm{FVC}$; SVC: slow vital capacity; IC: inspiratory capacity; IRV: inspiratory reserve volume; CT: computed tomography; TLC ${ }_{\mathrm{CT}}$ : $\mathrm{CT}$-measured total lung capacity; $\mathrm{RV}_{\mathrm{CT}}$ : CT-measured residual volume; $\mathrm{VC}_{\mathrm{CT}}$ : CT-measured vital capacity; average $P_{\mathrm{i} 10}$ : square root of wall area of a hypothetical airway with 10 mm internal perimeter; PRM ${ }^{\mathrm{EMPH}}$ : parametric response mapping of functional small airway disease as measures of emphysema; $\mathrm{PRM}{ }^{\mathrm{fSAD}}$ : parametric response mapping of functional small airway disease; Exp_-856: percentage of the lung voxels with attenuation <-856 Hounsfield Unit on the expiratory CT images; Insp_950: percentage of the lung voxels on inspiratory CT images with attenuation <-950 Hounsfield Units; 6-MWD: 6-minute walk distance; BODE: body-mass index, airflow obstruction, dyspnoea, and exercise capacity index; CAT: COPD assessment test; mMRC: modified Medical Research Council dyspnoea scale; SGRQ: Saint George's Respiratory Questionnaire; SF12: Short Form 12-Item Survey. \#: At least one follow-up spirometry was available for a subgroup of the patients. Reference equations: measures of pulmonary function and \% predicted of normal values were calculated using Crapo-predicted formulae [22-24]. Bronchodilator responsiveness was defined as $\geqslant 12 \%$ and $\geqslant 200 \mathrm{~mL}$ increase in FEV $\mathrm{V}_{1}$ after bronchodilator administration. 
TABLE 2 Associations of changes in lung function or symptoms with computed tomograpy-measured residual volume/total lung capacity $\left(\mathrm{RV}_{\mathrm{CT}} / \mathrm{TLC}_{\mathrm{CT}}\right)$

\begin{tabular}{|c|c|c|c|}
\hline Outcome parameters & Parameter estimate for $\mathbf{R V}_{\mathrm{CT}} / \mathrm{TLC}_{\mathrm{CT}} \%$ & $95 \% \mathrm{Cl}$ & p-value \\
\hline $\mathrm{FEV}_{1} \mathrm{~mL}$ & -1.98 & -4.92 to 0.98 & 0.193 \\
\hline FVC mL & 1.64 & -2.43 to 5.81 & 0.436 \\
\hline $\mathrm{FEV}_{1} / \mathrm{FVC} \%$ & -0.11 & -0.17 to -0.06 & $<0.001$ \\
\hline $\mathrm{FEF}_{25-75 \%} \mathbf{~ m L}$ & -7.72 & -13.94 to -1.56 & 0.015 \\
\hline $\mathrm{FEF}_{75 \%} \mathbf{m L}$ & -3.91 & -7.30 to -0.55 & 0.024 \\
\hline Expiratory time s & -0.002 & -0.045 to 0.041 & 0.927 \\
\hline 6-MWD m & -0.75 & -1.82 to 0.31 & 0.170 \\
\hline BODE index & 0.012 & 0.001 to 0.024 & 0.040 \\
\hline CAT score & 0.006 & -0.070 to 0.082 & 0.879 \\
\hline mMRC & 0.008 & -0.001 to 0.018 & 0.098 \\
\hline SGRQ total score & 0.046 & -0.108 to 0.204 & 0.566 \\
\hline SGRQ symptom score & -0.038 & -0.285 to 0.228 & 0.768 \\
\hline SGRQ activity score & 0.17 & -0.03 to 0.37 & 0.098 \\
\hline SGRQ impact score & -0.001 & -0.146 to 0.145 & 0.984 \\
\hline SF12 physical component & -0.04 & -0.10 to 0.02 & 0.163 \\
\hline SF12 physical functioning & -0.07 & -0.14 to 0.01 & 0.074 \\
\hline
\end{tabular}

Association of changes in lung function and symptoms outcomes with $\mathrm{RV}_{\mathrm{CT}} / \mathrm{TLC}_{\mathrm{CT}}$ were estimated using mixed-effect linear regression models with adjustment for age, sex, height, weight, smoking status, smoking burden, and random effects from length of follow-up and study sites. $\mathrm{FEV}_{1}$ : forced expiratory volume in 1 second; FVC: forced vital capacity; $\mathrm{FEF}_{25-75 \%}$ : forced expiratory flow at $25-75 \%$ of $\mathrm{FVC} \mathrm{FEF}_{75 \%}$ : forced expiratory flow at 75\% of FVC; 6-MWD: 6-minute walk distance test; BODE: body-mass index airflow obstruction, dyspnoea and exercise capacity; CAT: COPD assessment test; mMRC: modified Medical Research Council dyspnoea scale; SGRQ: Saint George's Respiratory Questionnaire; SF12: Short Form 12 Item survey. p-values are from mixed-effect linear regression modelling with a nested random subject and site effect. Significant associations are shown in bold.

The changes in $\mathrm{FEV}_{1}$ and $\mathrm{FVC}$ (or forced expiratory flow at $25-75 \%$ of $\mathrm{FVC}\left(\mathrm{FEF}_{25-75 \%}\right.$ ) and forced expiratory flow at $75 \%$ of $\mathrm{FVC}\left(\mathrm{FEF}_{75 \%}\right)$ ) were not statistically significantly different between the $\mathrm{RV}_{\mathrm{CT}} /$ $\mathrm{TLC}_{\mathrm{CT}}$ strata during the follow-up period. However, the decline in $\mathrm{FEV}_{1} / \mathrm{FVC}$ was, at least in part, due to a relative increase in FVC among those with high $\mathrm{RV}_{\mathrm{CT}} / \mathrm{TLC}_{\mathrm{CT}}$ compared to those with low $\mathrm{RV}_{\mathrm{CT}} / \mathrm{TLC}_{\mathrm{CT}}$ (tables 2 and 3 and figure 4).

Smoking status (current versus former smoker) or burden (pack-years of smoking) did not significantly contribute to any of the observed associations, nor did the interaction term between smoking status and $\mathrm{RV}_{\mathrm{CT}} / \mathrm{TLC}_{\mathrm{CT}}$ (supplementary table S5).

\section{Association of other CT measures of air trapping, emphysema and airway disease with progression to spirometric COPD}

Similar to $\mathrm{RV}_{\mathrm{CT}} / \mathrm{TLC}_{\mathrm{CT}}, \mathrm{PRM}^{\mathrm{fSAD}}$ and $\mathrm{Exp}_{-856}$ showed wide but less varied distributions across $\mathrm{FEV}_{1} /$ FVC and $\mathrm{FEV}_{1}$ (supplementary figures S3 and S4). Among the 496 subjects with high $\mathrm{VC}_{\mathrm{CT}}$ and SVC concordance and follow-up data, $\mathrm{FEV}_{1} / \mathrm{FVC}$ declined in $\mathrm{PRM}^{\mathrm{fSAD}}$ - and $\mathrm{Exp}_{-856}$-dependent manners such that those in high and intermediate tertiles for either $\mathrm{PRM}^{\mathrm{fSAD}}$ or $\mathrm{Exp}_{-856}$ had greater decline compared to those in the low tertile ( $\mathrm{p}$-values of 0.038 and 0.035 for $\mathrm{PRM}^{\mathrm{fSAD}}$ and $\mathrm{Exp}_{-856}$, respectively, for $\mathrm{FEV}_{1}$ / FVC decline) (supplementary tables S6, S7 and S8). Accordingly, those in the groups with higher $\mathrm{PRM}^{\mathrm{fSAD}}$ or $\mathrm{Exp}_{-856}$ were more likely to progress to develop spirometric COPD (supplementary table S9). Similar to what was observed with lung volumes, smoking status (current versus former smoker) or burden (pack-years of smoking) did not significantly contribute to any of the observed associations, nor did the interaction terms between smoking status and $\mathrm{PRM}^{\mathrm{fSAD}}$ or $\operatorname{Exp}_{-856}$ (supplementary table S10).

Other CT indices of emphysema and airway disease examined, including PRM ${ }^{\mathrm{EMPH}}$, Insp_950 and $P_{\mathrm{i} 10}$, were not associated with progression to spirometric COPD (supplementary table S11).

To better understand the importance of $\mathrm{RV}_{\mathrm{CT}} / \mathrm{TLC}_{\mathrm{CT}}$ compared with other $\mathrm{CT}$ parameters, we included all measured CT indices of air trapping, emphysema and airway wall thickness in the same model along with $\mathrm{RV}_{\mathrm{CT}} / \mathrm{TLC}_{\mathrm{CT}}$. In this all-inclusive and fully adjusted model, $\mathrm{RV}_{\mathrm{CT}} / \mathrm{TLC}_{\mathrm{CT}}$ (included as either a continuous or a categorical variable) was the only significant predictor for $\mathrm{FEV}_{1} / \mathrm{FVC}$ decline and COPD development in smokers with preserved spirometry (supplementary table S12). 
TABLE 3 Associations of changes in lung function or symptoms with computed tomography-measured residual volume/total lung capacity $\left(\mathrm{RV}_{\mathrm{CT}} / \mathrm{TLC}_{\mathrm{CT}}\right)$ strata

\begin{tabular}{|c|c|c|c|c|}
\hline Outcome parameters & $\mathbf{R V}_{\mathrm{CT}} / \mathrm{TLC}_{\mathrm{CT}}$ strata & Differences in estimates & $95 \% \mathrm{Cl}$ & p-value \\
\hline \multicolumn{5}{|l|}{$\mathrm{FEV}_{1} \mathrm{~mL}$} \\
\hline & High & -20.2 & -66.8 to 26.3 & \\
\hline & Intermediate & -23.7 & -65.2 to 18.5 & 0.525 \\
\hline & Low & Ref. & & \\
\hline \multicolumn{5}{|l|}{ FVC mL } \\
\hline & High & 29.3 & -35.1 to 94.5 & \\
\hline & Intermediate & 4.6 & -53.9 to 62.7 & 0.623 \\
\hline & Low & Ref. & & \\
\hline \multicolumn{5}{|l|}{ FEV $_{1} /$ FVC $\%$} \\
\hline & High & -1.43 & -2.31 to -0.57 & \\
\hline & Intermediate & -0.91 & -1.69 to -0.12 & 0.005 \\
\hline & Low & Ref. & & \\
\hline \multicolumn{5}{|l|}{$\mathbf{F E F}_{25-75 \%} \mathbf{~ m L}$} \\
\hline & High & -86.2 & -185.5 to 12.2 & \\
\hline & Intermediate & -77.4 & -165.7 to 11.4 & 0.164 \\
\hline & Low & Ref. & & \\
\hline \multicolumn{5}{|l|}{$\mathrm{FEF}_{75 \%} \mathbf{m L}$} \\
\hline & High & -53.2 & -107.8 to 1.0 & \\
\hline & Intermediate & -42.7 & -91.7 to 6.7 & 0.127 \\
\hline & Low & Ref. & & \\
\hline \multicolumn{5}{|l|}{ Expiratory time s } \\
\hline & High & 0.13 & -0.55 to 0.81 & \\
\hline & Intermediate & 0.60 & -0.02 to 1.21 & 0.120 \\
\hline & Low & Ref. & & \\
\hline \multicolumn{5}{|l|}{ 6-MWD m } \\
\hline & High & -15.4 & -32.2 to 1.2 & \\
\hline & Intermediate & -19.4 & -34.6 to -4.2 & 0.041 \\
\hline & Low & Ref. & & \\
\hline \multicolumn{5}{|l|}{ BODE index } \\
\hline & High & 0.20 & 0.02 to 0.39 & \\
\hline & Intermediate & 0.16 & -0.01 to 0.32 & 0.074 \\
\hline & Low & Ref. & & \\
\hline \multicolumn{5}{|l|}{ CAT score } \\
\hline & High & -0.007 & -1.208 to 1.202 & \\
\hline & Intermediate & -0.019 & -1.133 to 1.089 & 0.999 \\
\hline & Low & Ref. & & \\
\hline \multicolumn{5}{|l|}{ mMRC } \\
\hline & High & 0.175 & 0.025 to 0.327 & \\
\hline & Intermediate & 0.172 & 0.033 to 0.311 & 0.031 \\
\hline & Low & Ref. & & \\
\hline \multicolumn{5}{|l|}{ SGRQ total score } \\
\hline & High & 1.68 & -0.72 to 4.12 & \\
\hline & Intermediate & 0.18 & -2.05 to 2.45 & 0.312 \\
\hline & Low & Ref. & & \\
\hline \multicolumn{5}{|l|}{ SGRQ symptom score } \\
\hline & High & 1.99 & -1.84 to 6.02 & \\
\hline & Intermediate & 1.23 & -2.33 to 4.88 & 0.604 \\
\hline & Low & Ref. & & \\
\hline \multicolumn{5}{|l|}{ SGRQ activity score } \\
\hline & High & 3.28 & 0.10 to 6.50 & \\
\hline & Intermediate & 1.49 & -1.51 to 4.45 & 0.138 \\
\hline & Low & Ref. & & \\
\hline \multicolumn{5}{|l|}{ SGRQ impact score } \\
\hline & High & 0.99 & -1.31 to 3.32 & \\
\hline & Intermediate & 0.34 & -1.77 to 2.47 & 0.692 \\
\hline & Low & Ref. & & \\
\hline \multicolumn{5}{|c|}{ SF12 physical component } \\
\hline & High & -0.74 & -1.72 to 0.20 & \\
\hline & Intermediate & -0.67 & -1.56 to 0.19 & 0.231 \\
\hline & Low & Ref. & & \\
\hline
\end{tabular}




\begin{tabular}{|c|c|c|c|c|}
\hline Outcome parameters & $\mathbf{R V}_{\mathrm{CT}} / \mathrm{TLC}_{\mathrm{CT}}$ strata & Differences in estimates & $95 \% \mathrm{Cl}$ & $\mathrm{p}$-value \\
\hline \multicolumn{5}{|c|}{ SF12 physical functioning } \\
\hline & High & -1.39 & -2.58 to -0.26 & \\
\hline & Intermediate & -1.33 & -2.39 to -0.30 & 0.022 \\
\hline & Low & Ref. & & \\
\hline
\end{tabular}

Association of changes in lung function and symptoms outcomes with computed tomography-measured residual volume/total lung capcity $\left(\mathrm{RV}_{\mathrm{CT}} / \mathrm{TLC}_{\mathrm{CT}}\right)$ strata were estimated using mixed-effect linear regression models with adjustment for age, sex, height, weight, smoking status, smoking burden, and random effects from length of follow-up time and study site. $\mathrm{FEV}_{1}$ : forced expiratory volume in $1 \mathrm{~s}$; FVC: forced vital

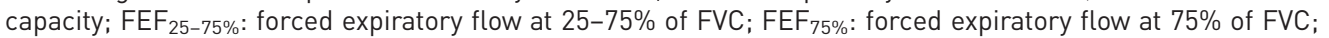
6-MWD: 6-minute walk distance test; BODE: body-mass index, airflow obstruction, dyspnoea and exercise capacity; CAT: COPD assessment test; mMRC: modified Medical Research Council dyspnoea scale; SGRQ: Saint George's Respiratory Questionnaire; SF12: Short Form 12-Item survey; Ref: reference value. p-values are from mixed-effect linear regression modelling with a nested random subject and site effect. Significant associations are shown in bold.

\section{Association of lung volumes with exercise capacity, symptoms, and respiratory exacerbations}

Among the 496 subjects with high $\mathrm{VC}_{\mathrm{CT}}$ and SVC concordance and follow-up data, the subjects with higher $\mathrm{RV}_{\mathrm{CT}} / \mathrm{TLC}_{\mathrm{CT}}$ (intermediate and high tertiles) walked a shorter distance on their subsequent 6-MWD testing compared with those with low $\mathrm{RV}_{\mathrm{CT}} / \mathrm{TLC}_{\mathrm{CT}}(\mathrm{p}=0.041)$ (tables 2 and 3). For example, subjects with high and intermediate $\mathrm{RV}_{\mathrm{CT}} / \mathrm{TLC}_{\mathrm{CT}}$ had a differential 6-MWD decline of $15 \mathrm{~m}$ and $19 \mathrm{~m}$, respectively, compared with those with low $\mathrm{RV}_{\mathrm{CT}} / \mathrm{TLC}_{\mathrm{CT}}$, reflecting an absolute decline in 6-MWD distance of $22 \mathrm{~m}$ to $30 \mathrm{~m}$ in those with higher $\mathrm{RV}_{\mathrm{CT}} / \mathrm{TLC}_{\mathrm{CT}}$ (supplementary table S13).

Similarly, subjective assessments of physical activity as measured by SF12 and SGRQ questionnaires showed a higher decline in the self-described level of subject activity in those with high and intermediate $\mathrm{RV}_{\mathrm{CT}} / \mathrm{TLC}_{\mathrm{CT}}$ compared with those with low $\mathrm{RV}_{\mathrm{CT}} / \mathrm{TLC}_{\mathrm{CT}}$ although this effect was not statistically significant when measured by SGRQ activity score $(\mathrm{p}=0.138)$ (tables 2 and 3). Other CT indices of air
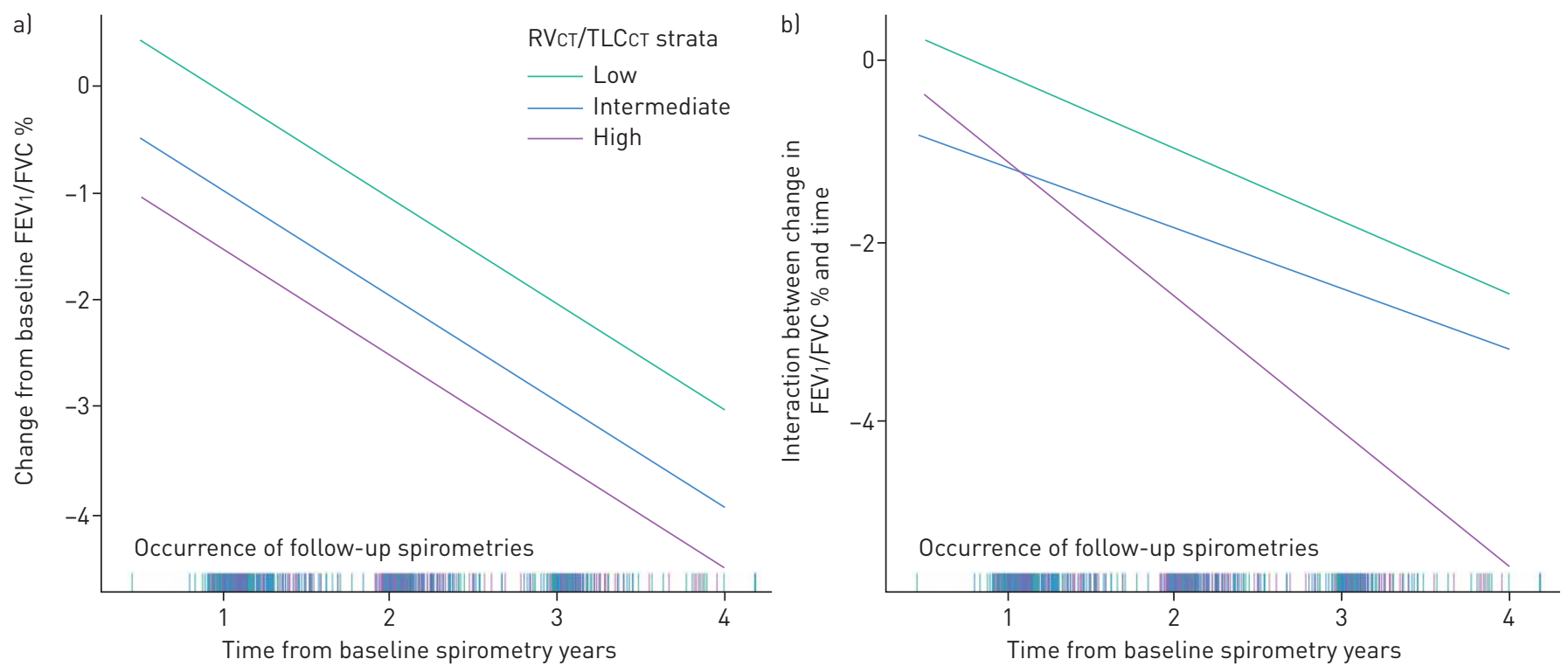

FIGURE 3 Comparison of change in spirometry from different SPIROMICS visits across CT-measured RV/TLC (RV $\left.\mathrm{RT}_{\mathrm{CT}} / \mathrm{TLC}_{\mathrm{CT}}\right)$ strata. Line graphs of $\mathrm{FEV}_{1} / \mathrm{FVC}$ values predicted from mixed-effect regression modelling ("fitted values") through time across $\mathrm{RV}_{\mathrm{CT}} / \mathrm{TLC}_{\mathrm{CT}}$ strata. Subjects were stratified into tertiles of $\mathrm{RV}_{\mathrm{CT}} / \mathrm{TLC}_{\mathrm{CT}}$ represented by green, blue and magenta for low, intermediate and high $\mathrm{RV}_{\mathrm{CT}} / \mathrm{TLC}_{\mathrm{CT}}$ tertiles, respectively. The tick marks on the $x$-axes represent the time that each spirometry was performed during the course of the study. Panel a shows the change in $\mathrm{FEV}_{1} / \mathrm{FVC}$ (predicted from the main model) and panel b shows the difference in rate of $\mathrm{FEV}_{1} / \mathrm{FVC}$ change per year (predicted from the spirometry follow-up time interaction modell. $\mathrm{FEV}_{1}$ : forced expiratory volume in $1 \mathrm{~s}$; FVC: forced vital capacity. 
TABLE 4 Association of spirometric COPD development with computed tomography-measured residual volume/total lung capacity $\left(\mathrm{RV}_{\mathrm{CT}} / \mathrm{TLC}_{\mathrm{CT}}\right)$

\begin{tabular}{|c|c|c|c|c|}
\hline $\begin{array}{l}\text { Progression to spirometric } \\
\text { COPD }\end{array}$ & At V2 & At V3 & At V4 & On last follow-up\# \\
\hline Subjects $\mathrm{n}$ & 496 & 295 & 157 & 496 \\
\hline $\mathrm{RV}_{\mathrm{CT}} / \mathrm{TLC}_{\mathrm{CT}} \%$ & $\begin{array}{c}1.081(1.028-1.136) \\
p=0.002\end{array}$ & $\begin{array}{c}1.091(1.034-1.151) \\
p=0.001\end{array}$ & $\begin{array}{c}1.048(0.971-1.130) \\
p=0.230\end{array}$ & $\begin{array}{c}1.108(1.056-1.162) \\
p<0.001\end{array}$ \\
\hline \multicolumn{5}{|l|}{ Categorical model } \\
\hline Intermediate $\mathrm{RV}_{\mathrm{CT}} / \mathrm{TLC} \mathrm{C}_{\mathrm{CT}}$ & $\begin{array}{c}2.763(1.183-6.452) \\
p=0.019\end{array}$ & $\begin{array}{c}2.420(0.921-6.361) \\
p=0.073\end{array}$ & $\begin{array}{c}2.955(0.822-10.625) \\
p=0.097\end{array}$ & $\begin{array}{c}2.966(1.298-6.775) \\
p=0.010\end{array}$ \\
\hline Low $\mathrm{RV}_{\mathrm{CT}} / \mathrm{TLC}_{\mathrm{CT}}$ & Ref. & Ref. & Ref. & Ref. \\
\hline
\end{tabular}

Association of development of spirometric COPD with $\mathrm{RV}_{\mathrm{CT}} / T L \mathrm{C}_{\mathrm{CT}}$ was estimated using mixed effect logistic regression models with adjustment for age, sex, height, weight, smoking status, smoking burden, and random effects from length of follow-up and study sites. The models odds ratio with $95 \%$ confidence intervals and $\mathrm{p}$-values are shown in the table. Ref: reference value. $\mathrm{p}$-values are from mixed effect logistic regression with random effect. "\#: follow-up spirometry from the last available post-bronchodilator spirometry from any of the visit 2 , visit 3 , visit 4, (V2, V3, or V4) or the last follow-up visit available.

trapping $\left(\mathrm{PRM}^{\mathrm{fSAD}}\right.$ or $\mathrm{Exp}_{-856}$ ) were not associated with changes in exercise capacity (supplementary tables S6 and S7).

Higher $\mathrm{RV}_{\mathrm{CT}} / \mathrm{TLC}_{\mathrm{CT}}$ was statistically significantly associated with worsening respiratory symptom scores measured only by mMRC ( $\mathrm{p}=0.031)$. Changes in symptoms measured by SGRQ and CAT, although in the hypothesised direction, were not statistically significant (tables 2 and 3). The BODE index also showed a trend towards an $\mathrm{RV}_{\mathrm{CT}} / \mathrm{TLC}_{\mathrm{CT}}$-dependent worsening with higher $\mathrm{RV}_{\mathrm{CT}} / \mathrm{TLC}_{\mathrm{CT}}$, but this did not reach
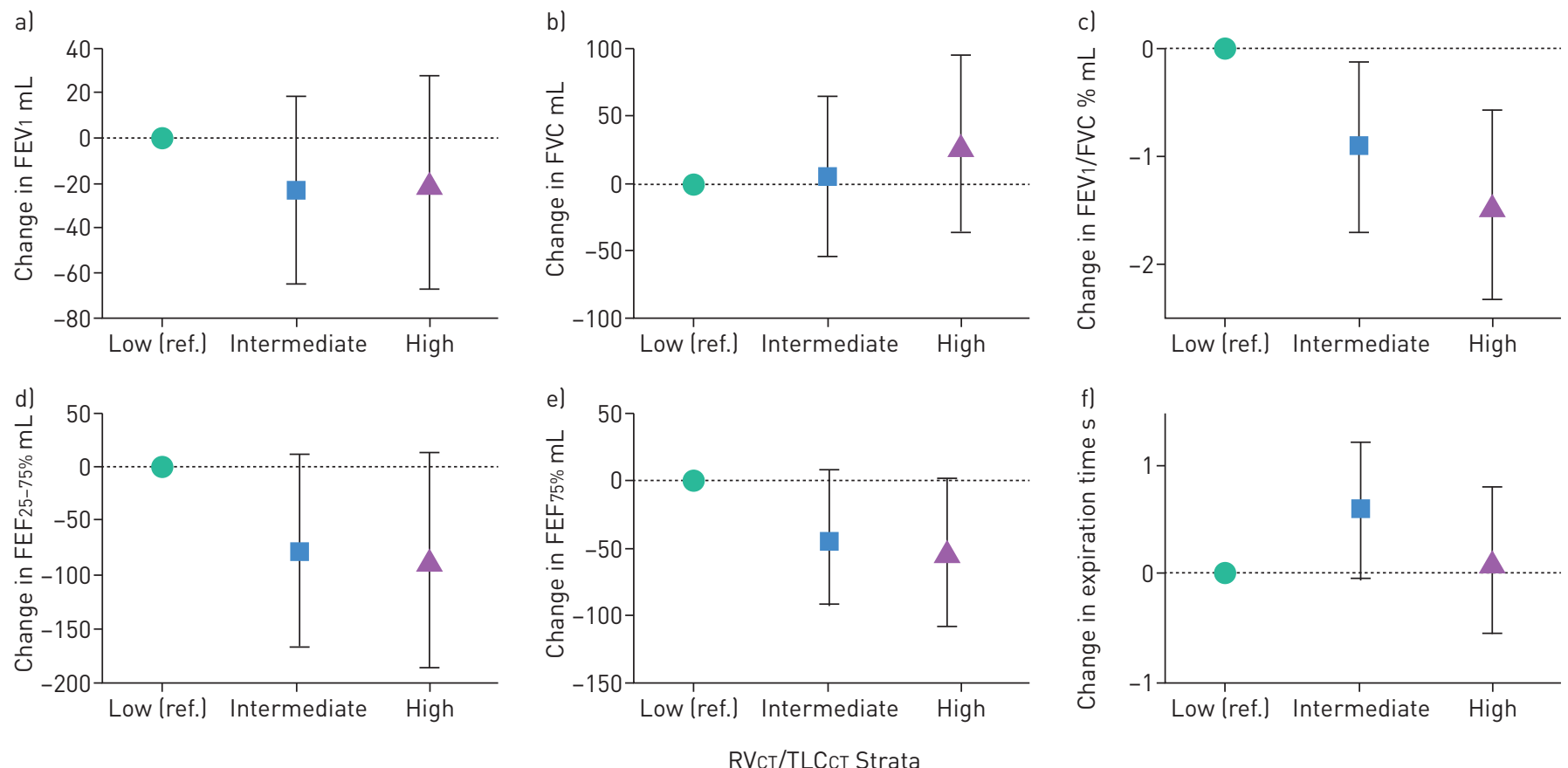

FIGURE 4 Comparison of change in airflow indices on follow-up spirometry across CT-measured RV/TLC (RV $\left.\mathrm{CT}_{\mathrm{C}} / \mathrm{TLC}_{\mathrm{CT}}\right)$ strata. Graphs represent means and $95 \%$ confidence intervals for change in airflow indices across $\mathrm{RV}_{\mathrm{CT}} / \mathrm{TLC}_{\mathrm{CT}}$ strata relative to the reference group (subjects in the lowest tertile of $\mathrm{RV}_{\mathrm{CT}} / \mathrm{TLC}_{\mathrm{CT}}$ ) from mixed-effect linear regression modelling with adjustment for age, sex, height, weight, smoking status (former versus current), baseline lung function and time to follow-up spirometry. Subjects were stratified into tertiles of $\mathrm{RV}_{\mathrm{CT}} / \mathrm{TLC}_{\mathrm{CT}}$ represented by green, blue and magenta for low, intermediate and high $\mathrm{RV}_{\mathrm{CT}} / \mathrm{TLC}_{\mathrm{CT}}$ tertiles, respectively. Ref: reference value; $\mathrm{FEV}_{1}$ : forced expiratory volume in $1 \mathrm{~s}$; $\mathrm{FVC}$ : forced vital capacity; $\mathrm{FEF}_{25-75 \%}$ : forced expiratory flow at $25-75 \%$ of $F V C ; F^{2} F_{75 \%}$ : forced expiratory flow at $75 \%$ of $F V C$. 
statistical significance $(\mathrm{p}=0.074)$. Other CT indices $\left(\mathrm{PRM}^{\mathrm{fSAD}}\right.$ or $\left.\mathrm{Exp}_{-856}\right)$ were not associated with changes in respiratory symptoms (supplementary tables S6 and S7).

The time and $\mathrm{RV}_{\mathrm{CT}} / \mathrm{TLC}_{\mathrm{CT}}$ interaction analyses were not statistically significant with any of the measured exercise or symptoms score outcomes (supplementary table S4).

Among the 618 subjects with high $\mathrm{VC}_{\mathrm{CT}}$ and SVC concordance, a total of 36 subjects had severe respiratory exacerbation events (including emergency department and hospital admissions). Neither the number of those events nor the time to the first hospitalisation was significantly different between the tertiles of $\mathrm{RV}_{\mathrm{CT}} / \mathrm{TLC}_{\mathrm{CT}}$, $\mathrm{PRM}^{\mathrm{fSAD}}$, or Exp-856 (supplementary table S14).

\section{Sensitivity analyses}

Among the 496 subjects with high $\mathrm{VC}_{\mathrm{CT}}$ and SVC concordance and follow-up data, $37.1 \%$ of patients were obese (BMI >30), 16.7\% had asthma diagnoses and $12.1 \%$ had bronchodilator responsiveness. Sensitivity analyses with exclusion of patients with obesity, asthma or bronchodilator responsiveness did not change any of the observed associations, with the exception of one of the outcomes (the continuous $\mathrm{RV}_{\mathrm{CT}} / \mathrm{TLC}_{\mathrm{CT}}$ model of progression to COPD measured at V3) becoming non-significant ( $\left.\mathrm{p}=0.097\right)$ when obese subjects were excluded. Sensitivity analyses with simultaneous inclusion of bronchodilator responsiveness (in terms of $\mathrm{FEV}_{1}$ ) and hip-to-waist ratio in the models did not affect any of the observed associations except for change in 6-MWD test, which showed similar but a non-significant association $(\mathrm{p}=0.072)$. Inclusion of symptom score $(\mathrm{CAT}<$ or $\geqslant 10)$ in the models along with $\mathrm{RV}_{\mathrm{CT}} / \mathrm{TLC}_{\mathrm{CT}}$ or other $\mathrm{CT}$ indices of air trapping $\left(\mathrm{PRM}^{\mathrm{fSAD}}\right.$ or $\left.\mathrm{Exp}_{-856}\right)$ did not affect the observed associations.

Furthermore, use of lower limit of normal criteria for diagnosis of COPD, instead of fixed ratio per GOLD criteria, produced similar associations between $\mathrm{RV}_{\mathrm{CT}} / \mathrm{TLC}_{\mathrm{CT}}$ and outcomes (supplementary tables $\mathrm{S} 15$, S16, and S17).

Finally, sensitivity analysis with inclusion of all 814 subjects regardless of their $\mathrm{VC}_{\mathrm{CT}}$ and SVC concordance did not affect the overall associations of RV/TLC with lung function outcomes.

\section{Discussion}

In this longitudinal study of a prospective cohort of smokers at risk for COPD but with preserved spirometry, we found radiographically-measured $\mathrm{RV}$ to TLC ratio $\left(\mathrm{RV}_{\mathrm{CT}} / \mathrm{TLC}_{\mathrm{CT}}\right)$ to vary widely across the normal ranges of spirometric indices used for COPD definition $\left(\mathrm{FEV}_{1} / \mathrm{FVC}\right.$ and $\left.\mathrm{FEV}_{1}\right)$. We then explored this wide variance and found patients with higher $\mathrm{RV}_{\mathrm{CT}} / \mathrm{TLC}_{\mathrm{CT}}$ to have greater decline in lung function at a faster rate, greater likelihood of developing spirometric COPD, and greater reduction in exercise capacity compared with those with lower $\mathrm{RV}_{\mathrm{CT}} / \mathrm{TLC}_{\mathrm{CT}}$. The relationship between higher $\mathrm{RV}_{\mathrm{CT}} / \mathrm{TLC}_{\mathrm{CT}}$ and worse respiratory symptoms as measured by respiratory questionnaires reached statistical significance only across one of the three survey tools used. These findings were robust, as adjustment of analyses for several possible confounders, including smoking status (current versus former smoker), smoking burden (packyears of smoking), obesity (including hip-to-waist ratio), concomitant asthma, respiratory symptoms score (score of $<$ versus $\geqslant 10$ on CAT questionnaire) or bronchodilator responsiveness, did not change the observed associations. Furthermore, CT indices of air trapping including $\mathrm{PRM}^{\mathrm{fSAD}}$ and $\mathrm{Exp}_{-856}$ also showed similar patterns of association with the $\mathrm{FEV}_{1} / \mathrm{FVC}$ decline and progression to COPD. Remarkably, when all CT parameters of air trapping, emphysema, and airway disease were analysed together in the same model, the $\mathrm{RV}_{\mathrm{CT}} / \mathrm{TLC}_{\mathrm{CT}}$ was the only significant predictor for lung function decline and progression to spirometric COPD in smokers with preserved spirometry.

In a previous retrospective study of electronic health records from the Veterans Health Administration [9], we found plethysmographically-measured RV/TLC, as well as other lung volume indices that represent air trapping (such as the ratio of functional residual capacity (FRC) to TLC), to predict morbidity and progression to COPD in smokers with preserved spirometry. The current study increases our confidence in those conclusions by providing prospective validation of the findings of that study and expands our understanding of multi-dimensionality of susceptibility to develop COPD. Overall, these findings indicate the predictive usefulness of lung volume measurements, regardless of whether determined radiographically or physiologically, and argue for use of air trapping parameters for prognostication in those at risk for COPD.

Given the baseline differences in spirometric indices between those with higher and lower $\mathrm{RV}_{\mathrm{CT}} / \mathrm{TLC}_{\mathrm{CT}}$ in this cohort, a possible explanation for the faster rate of lung function decline may simply be that those with higher $\mathrm{RV}_{\mathrm{CT}} / \mathrm{TLC}_{\mathrm{CT}}$ had longer duration or higher amount of smoking, causing them to have more prolonged or more severe lung damage. However, the association of $\mathrm{RV}_{\mathrm{CT}} / \mathrm{TLC}_{\mathrm{CT}}$ with progression to COPD was unaffected by adjustment for baseline lung function, smoking status (being former versus current smoker) or the amount of smoking (pack-years) in these unobstructed subjects with a minimum 
of 20 pack-years of smoking. Indeed, these data suggest that once at least 20 pack-years of smoking has been achieved, even smoking cessation does not affect the subsequent lung function decline in those unobstructed smokers who have developed air trapping. Overall, these findings suggest that distinct underlying biological mechanisms may be involved in determining susceptibility of smokers to develop COPD as has been previously suggested in "the Dutch hypothesis" [21], and that lung volumes representing air trapping may provide early evidence for identifying the "susceptible" smokers.

An interesting finding in this study is the manner by which the $\mathrm{FEV}_{1} / \mathrm{FVC}$ ratio declined in those with high $\mathrm{RV}_{\mathrm{CT}} / \mathrm{TLC}_{\mathrm{CT}}$ to reach the threshold to be considered COPD (i.e. $\mathrm{FEV}_{1} / \mathrm{FVC}<0.70$ ). Although the differential changes in $\mathrm{FEV}_{1}$ or $\mathrm{FVC}$ across $\mathrm{RV}_{\mathrm{CT}} / \mathrm{TLC}_{\mathrm{CT}}$ strata did not reach statistical significance, there appeared to be contributions from decline in $\mathrm{FEV}_{1}$ and increase in $\mathrm{FVC}$ as seen in figure 4. Our previous retrospective study of electronic health records from the Veterans Health Administration [9], showed statistically significant change in only FVC (and no change in $\mathrm{FEV}_{1}$ ) to contribute to the decline in $\mathrm{FEV}_{1}$ / FVC seen with higher RV/TLC and air trapping. Together, these findings may implicate increase in FVC as the important mechanism responsible for progression to spirometric COPD in the early stages of the disease. It is remarkable, however, that despite the trend of increases in FVC in those with higher $\mathrm{RV}_{\mathrm{CT}} /$ $\mathrm{TLC}_{\mathrm{CT}}$, there was not an increasing trend in the expiratory time on spirometry and, in fact, the expiratory time was shorter in those with higher baseline $\mathrm{RV}_{\mathrm{CT}} / \mathrm{TLC}_{\mathrm{CT}}$ and higher FVC on follow-up spirometry. These findings may indicate that regional loss of lung elastance with subsequent expansion of chest wall and increased TLC may contribute to the higher FVC and development of spirometric COPD [9].

Our study has several limitations. First, although in some subjects, assessing lung volumes using CT imaging was challenging, the majority of subjects had accurate RV and TLC measurements as we demonstrated by the high concordance between radiographically and physiologically measured VC. The cases of lung volume measurement inaccuracy by CT may be due to the challenges with breath-hold manoeuvres during the full inspiratory and expiratory CT imaging. Remarkably, the strength of the associations of lung volumes representing air trapping with lung function decline and COPD development was so robust that inclusion of all subjects versus stringent inclusion of only those with high $\mathrm{VC}_{\mathrm{CT}}$ and SVC concordance did not affect the study findings. Second, only limited number of repeat spirometries and relatively short duration of follow-up were available from the SPIROMICS cohort. Nevertheless, it is indeed remarkable that statistically significant changes in lung function albeit small were detected within the available follow-up duration. Lastly, while we found higher $\mathrm{RV}_{\mathrm{CT}} / \mathrm{TLC}_{\mathrm{CT}}$ to be associated with faster decline in lung function and exercise capacity over the follow-up period, we found statistically significant worsening of symptoms via only one of the three respiratory questionnaires used in SPIROMICS. However, other questionnaires did show a similar albeit non-significant trend towards worsening symptoms with higher $\mathrm{RV}_{\mathrm{CT}} / \mathrm{TLC}_{\mathrm{CT}}$. This may be due to the relatively short duration of follow-up available and/or the limited sensitivity of the survey tools that were used to assess the symptoms. A longer follow-up period may then provide further convincing evidence regarding symptom progression.

In conclusion, in smokers with preserved spirometry, radiographic lung volumes representing air trapping prospectively predict higher rate of spirometry decline and COPD development, and may be predictive of more rapid decline in exercise capacity and respiratory symptoms associated with COPD. Further investigation of underlying biological mechanisms involved in development of air trapping should be useful in understanding the susceptibility to develop COPD at its early stages.

Acknowledgements: The authors thank the SPIROMICS participants and participating physicians, investigators and staff for making this research possible. More information about the study and how to access SPIROMICS data are at www. spiromics.org. We would like to acknowledge the following current and former investigators of the SPIROMICS sites and reading centres: Neil E. Alexis, Wayne H. Anderson, Mehrdad Arjomandi, Igor Barjaktarevic, R. Graham Barr, Lori A. Bateman, Surya P. Bhatt, Eugene R. Bleecker, Richard C. Boucher, Russell P. Bowler, Stephanie A. Christenson, Alejandro P. Comellas, Christopher B. Cooper, David J. Couper, Gerard J. Criner, Ronald G. Crystal, Jeffrey L. Curtis, Claire M. Doerschuk, Mark T. Dransfield, Brad Drummond, Christine M. Freeman, Craig Galban, MeiLan K. Han, Nadia N. Hansel, Annette T. Hastie, Eric A. Hoffman, Yvonne Huang, Robert J. Kaner, Richard E. Kanner, Eric C. Kleerup, Jerry A. Krishnan, Lisa M. LaVange, Stephen C. Lazarus, Fernando J. Martinez, Deborah A. Meyers, Wendy C. Moore, John D. Newell Jr, Robert Paine, III, Laura Paulin, Stephen P. Peters, Cheryl Pirozzi, Nirupama Putcha, Elizabeth C. Oelsner, Wanda K. O'Neal, Victor E. Ortega, Sanjeev Raman, Stephen I. Rennard, Donald P. Tashkin, J. Michael Wells, Robert A. Wise and Prescott G. Woodruff. The project officers from the Lung Division of the National Heart, Lung, and Blood Institute were Lisa Postow and Lisa Viviano.

Author contributions: Conceived and designed the current study: M. Arjomandi. Developed study protocols: M. Arjomandi, S. Zeng, I. Barjaktarevic, R.G. Barr, E.R. Bleecker, R.P. Bowler, R.G. Buhr, G.J. Criner, A.P. Comellas, C. B. Cooper, D.J. Couper, J.L. Curtis, M.T. Dransfield, M.K. Han, N.N. Hansel, E.A. Hoffman, R.J. Kaner, R.E. Kanner, J. A. Krishnan, R. Paine III, S.P. Peters, S.I. Rennard and P.G. Woodruff. Collected data: I. Barjaktarevic, R.G. Barr, E.R. Bleecker, R.P. Bowler, R.G. Buhr, G.J. Criner, A.P. Comellas, C.B. Cooper, D.J. Couper, J J.L. Curtis, M.T. Dransfield, M. K. Han, N.N. Hansel, E.A. Hoffman, R.J. Kaner, R.E. Kanner, J.A. Krishnan, R. Paine III, S.P. Peters, S.I. Rennard and P. G. Woodruff. Analysed and interpreted data: M. Arjomandi, S. Zeng, I. Barjaktarevic, R.G. Barr, R.P. Bowler, R.G. Buhr, 
A.P. Comellas, C.B. Cooper, D.J. Couper, J.L. Curtis, M.T. Dransfield, M.K. Han, N.N. Hansel, E.A. Hoffman, R.J. Kaner, R.E. Kanner, J.A. Krishnan, R. Paine III, S.P. Peters, S.I. Rennard and P.G. Woodruff. Prepared and edited the manuscript: M. Arjomandi, S. Zeng, I. Barjaktarevic, R.G. Barr, R.P. Bowler, R.G. Buhr, A.P. Comellas, C.B. Cooper, D.J. Couper, J.L. Curtis, M.T. Dransfield, M.K. Han, N.N. Hansel, E.A. Hoffman, R.J. Kaner, R.E. Kanner, J.A. Krishnan, R. Paine III, S.P. Peters, S.I. Rennard and P.G. Woodruff. Obtained funding: M. Arjomandi, I. Barjaktarevic, R.G. Barr E.R. Bleecker, R.P. Bowler, R.G. Buhr, G.J. Criner, A.P. Comellas, C.B. Cooper, D.J. Couper, J.L. Curtis, M.T. Dransfield, M.K. Han, N.N. Hansel, E.A. Hoffman, R.J. Kaner, R.E. Kanner, J.A. Krishnan, R. Paine III, S.P. Peters, S.I. Rennard and P.G. Woodruff.

Support statement: SPIROMICS was supported by contracts from the NIH/NHLBI (HHSN268200900013C, HHSN268200900014C, HHSN268200900015C, HHSN268200900016C, HHSN268200900017C, HHSN268200900018C, HHSN268200900019C, HHSN268200900020C), and supplemented by contributions made through the Foundation for the NIH and the COPD Foundation from AstraZeneca/MedImmune, Bayer, Bellerophon Therapeutics; Boehringer Ingelheim Pharmaceuticals, Inc., Chiesi Farmaceutici S.p.A., Forest Research Institute, Inc., GlaxoSmithKline, Grifols Therapeutics, Inc., Ikaria, Inc., Novartis Pharmaceuticals Corporation, Nycomed GmbH, ProterixBio, Regeneron Pharmaceuticals, Inc., Sanofi, Sunovion, Takeda Pharmaceutical Company and Theravance Biopharma. Funding for the work on this manuscript was also provided by the Flight Attendant Medical Research Institute (M. Arjomandi). Funding information for this article has been deposited with the Crossref Funder Registry.

Conflict of interest: S. Zeng reports salary support from United States Department of Veterans Affairs, during the conduct of the study. I. Barjaktarevic reports grants from AMGEN, grants and personal fees from GE Healthcare, personal fees from Grifols, AstraZeneca, CSL Behring, Boehringer Ingelheim, Verona Pharma and Fisher and Pykel Healthcare, outside the submitted work. R.G. Barr reports grants from NIH, Foundation for the NIH and COPD Foundation, during the conduct of the study; grants from Alphal Foundation, personal fees (royalties) from UpToDate, outside the submitted work. E.R. Bleecker reports grants from SARP, AsthmaNET, SPIROMICS, Pharmacogenetics and Foundation NIH, involvement in clinical trials administered through Wake Forest School of Medicine for Amgen, AstraZeneca/MedImmune, Boehringer Ingelheim, Genentech/Roche, GlaxoSmithKline, Janssen/Johnson \& Johnson, Novartis, Pfizer, Sanofi-Regeneron and Teva, personal fees for consultancy from Amgen, AstraZeneca/MedImmune, Boehringer Ingelheim, Genentech/Roche, GlaxoSmithKline, Knopp, Novartis and Sanofi/Regeneron, outside the submitted work. R.P. Bowler reports having served on advistory boards for Boehringer-Ingelheim and Abbott Nutrition, outside the submitted work. R.G. Buhr reports personal fees from GlaxoSmithKline, outside the submitted work. G.J. Criner has nothing to disclose. A.P. Comellas reports grants from NIH, during the conduct of the study; non-financial support for consultancy from VIDA Diagnostics, outside the submitted work. C.B. Cooper has nothing to disclose. D.J. Couper reports grants from NHLBI (NIH) and COPD Foundation, during the conduct of the study; grants from NHLBI (NIH), outside the submitted work. J.L. Curtis reports grants from NIH/NHLBI (U01HL137880), during the conduct of the study; and grants from Department of Veterans Affairs (I01 CX000911), NIH/NIAID (R01 AI120526, R21 AI 117371), Department of Defense (W81XWH-15-1-0705, PR150432) and MedImmune, Corp. Ltd, outside the submitted work. M.T. Dransfield reports grants from NIH, during the conduct of the study; grants from Department of Defense, $\mathrm{NIH}$ and the American Lung Association, personal fees for consultancy and involvement with contracted clinical trials for Boehringer Ingelheim, GlaxoSmithKline, AstraZeneca, PneumRx/BTG and Boston Scientific, involvement with contracted clinical trials for Novartis, Yungjin and Pulmonx, personal fees for consultancy from Genentech, Quark Pharmaceuticals and Mereo, outside the submitted work. M.K. Han reports personal fees from GSK, BI and AZ, non-financial support from Novartis and Sunovion, outside the submitted work. N.N. Hansel reports grants and personal fees for consultancy from AstraZeneca and GSK, grants from Boehringer Ingelheim, NIH and COPD Foundation, personal fees for consultancy from Mylan, outside the submitted work. E.A. Hoffman reports grants from $\mathrm{NIH}$, during the conduct of the study; and is a founder and shareholder of VIDA Diagnostics, a company commercialising lung image analysis software developed, in part, at the University of Iowa. R.J. Kaner reports personal fees from Boehringer Ingelheim, Roche/Genentech, Medimmune/AstraZeneca, Gilead, Celgene and Janssen, outside the submitted work. R.E. Kanner has nothing to disclose. J.A. Krishnan has nothing to disclose. R. Paine III reports grants from NHLBI and COPD Foundation, during the conduct of the study; grants from Department of Veterans Affairs, outside the submitted work. S.P. Peters, reports grants from NIH, NHLBI as the PI of the Wake Forest Clinical Site for the SPIROMICS COPD Program, during the conduct of the study. S.I. Rennard is employed by AstraZeneca, Cambridge, UK and also retains Professorship and a part-time appointment at the the University of Nebraska Medical Center, Omaha, NE, USA. P.G. Woodruff reports personal fees for consultancy from Theravance, AstraZeneca, Regeneron, Sanofi, Genentech, Roche and Janssen, outside the submitted work. M. Arjomandi reports salary support from United States Department of Veterans Affairs, grants and salary support from United States National Institute of Health, during the conduct of the study.

\section{References}

1 Vestbo J, Lange P. Can GOLD Stage 0 provide information of prognostic value in chronic obstructive pulmonary disease? Am J Respir Crit Care Med 2002; 166: 329-332.

2 Lokke A, Lange P, Scharling H, et al. Developing COPD: a 25 year follow up study of the general population. Thorax 2006; 61: 935-939.

3 Pelkonen M, Notkola IL, Nissinen A, et al. Thirty-year cumulative incidence of chronic bronchitis and COPD in relation to 30-year pulmonary function and 40-year mortality: a follow-up in middle-aged rural men. Chest 2006; 130: 1129-1137.

4 Vestbo J, Hogg JC. Convergence of the epidemiology and pathology of COPD. Thorax 2006; 61: 86-88.

5 Mullen JB, Wright JL, Wiggs BR, et al. Reassessment of inflammation of airways in chronic bronchitis. $\mathrm{Br} \mathrm{Med} J$ (Clin Res Ed) 1985; 291: 1235-1239.

6 Saetta M, Turato G, Facchini FM, et al. Inflammatory cells in the bronchial glands of smokers with chronic bronchitis. Am J Respir Crit Care Med 1997; 156: 1633-1639.

7 Langer D, Ciavaglia CE, Neder JA, et al. Lung hyperinflation in chronic obstructive pulmonary disease: mechanisms, clinical implications and treatment. Expert Rev Respir Med 2014; 8: 731-749. 
8 Thomas M, Decramer M, O’Donnell DE. No room to breathe: the importance of lung hyperinflation in COPD. Prim Care Respir J 2013; 22: 101-111.

9 Zeng S, Tham A, Bos B, et al. Lung volume indices predict morbidity in smokers with preserved spirometry. Thorax 2019; 74: 114-124.

10 Couper D, LaVange LM, Han M, et al. Design of the Subpopulations and Intermediate Outcomes in COPD Study (SPIROMICS). Thorax 2014; 69: 491-494.

11 Global Initiative for Chronic Obstructive Lung Disease. Global strategy for the diagnosis, management, and prevention of Chronic Obstructive pulmonary disease. www.goldcopd.org Date last accessed: October 8, 2018.

12 Woodruff PG, Barr RG, Bleecker E, et al. Clinical significance of symptoms in smokers with preserved pulmonary function. N Engl J Med 2016; 374: 1811-1821.

13 Hankinson JL, Odencrantz JR, Fedan KB. Spirometric reference values from a sample of the general U.S. population. Am J Respir Crit Care Med 1999; 159: 179-187.

14 Guo J, Wang C, Chan KS, et al. A controlled statistical study to assess measurement variability as a function of test object position and configuration for automated surveillance in a multicenter longitudinal COPD study (SPIROMICS). Med Phys 2016; 43: 2598.

15 Busacker A, Newell JD, Jr., Keefe T, et al. A multivariate analysis of risk factors for the air-trapping asthmatic phenotype as measured by quantitative CT analysis. Chest 2009; 135: 48-56.

16 Hersh CP, Hokanson JE, Lynch DA, et al. Family history is a risk factor for COPD. Chest 2011; 140: 343-350.

17 Galban CJ, Boes JL, Bule M, et al. Parametric response mapping as an indicator of bronchiolitis obliterans syndrome after hematopoietic stem cell transplantation. Biol Blood Marrow Transplant 2014; 20: 1592-1598.

18 Labaki WW, Gu T, Murray S, et al. Voxel-wise longitudinal parametric response mapping analysis of chest computed tomography in smokers. Acad Radiol 2019; 26: 217-223.

19 Nakano Y, Wong JC, de Jong PA, et al. The prediction of small airway dimensions using computed tomography. Am J Respir Crit Care Med 2005; 171: 142-146.

20 Multiple Regression/Correlation With Two or More Independent Variables. In: Cohen J, Cohen PC, West SG, et al., eds. Applied Multiple Regression/Correlation Analysis For The Behavioral Sciences. New York, Routledge, 2003; pp. 64-85.

21 Sluiter HJ, Koeter GH, de Monchy JG, et al. The Dutch hypothesis (chronic non-specific lung disease) revisited. Eur Respir J 1991; 4: 479-489.

22 Crapo RO, Casaburi R, Coates AL, et al. Guidelines for methacholine and exercise challenge testing-1999. This official statement of the American Thoracic Society was adopted by the ATS Board of Directors, July 1999. Am J Respir Crit Care Med 2000; 161: 309-329.

23 Crapo RO, Morris AH, Gardner RM. Reference spirometric values using techniques and equipment that meet ATS recommendations. Am Rev Respir Dis 1981; 123: 659-664.

24 Crapo RO, Morris AH, Gardner RM. Reference values for pulmonary tissue volume, membrane diffusing capacity, and pulmonary capillary blood volume. Bull Eur Physiopathol Respir 1982; 18: 893-899. 